\title{
PROGNOSIS OF ISOLATED VENTRICULAR SEPTAL DEFECTS
}

\author{
BY \\ E. MANNHEIMER, D. IKKOS, AND B. JONSSON \\ From the Pediatric Clinic, Karolinska Sjukhuset, Stockholm, Sweden
}

Received July 17, 1956

The diagnosis of ventricular septal defects (V.S.D.) during life was made more reliable by the introduction of cardiac catheterization (Wood et al., 1955; Kjellberg et al., 1955; Selzer, 1954; Blount, 1955). The old clinical syndromes such as Roger's disease and Eisenmenger's complex do not cover all the types. One of the aims of this paper is to evaluate the severity of our cases in order to determine the prognosis and the indications for operation. The classification as well as the clinical judgment are mostly based on observations made in a previous work by Kjellberg et al. (1955). Their results, together with our increased experience from about 20 new cases, will form the basis for this study.

Anatomy and Hamodynamics. The old concept that benign ventricular septal defects are located in the muscular part of the septum (low V.S.D.) and the severe ones in the membranous septum (high V.S.D.) is incorrect. The great majority are situated in the membranous septum. The size of the defect and the resistance in the two circulations determine the size and direction of the shunt and also the pressure in the lesser circulation (Selzer, 1954). If the defect is big, $1.5-3 \mathrm{~cm}$. (Selzer, 1954), the pressures in both ventricles may become equilibrated. When the pulmonary resistance is low and the defect is big the left-to-right shunt will be large. With increasing pulmonary resistance the shunt will be smaller and its direction left-to-right, right-to-left, or mixed.

\section{MATERIAL}

The material consists of 72 patients, aged from 3 months to 20 years, who were admitted to our clinic from 1951 to 1955. Every case had a complete clinical examination including phonocardiography, electrocardiography, roentgenography, and cardiac catheterization. In addition in some instances angiocardiography was also performed. There was equal distribution according to sex, i.e. 35 girls and 37 boys. All cases with complicating pulmonary stenosis or other malformations were excluded from this study. Fig. 1 shows the classification of cases into three main groups, with sub-divisions (see legend to Figure). There were four deaths, all small children aged 1-2 years (Group III).

\section{RESULTS}

In the most severe cases definite cardiac symptoms were already present in infancy. An improvement in health could often be noted after the first year of life. Physical under-development was not seen frequently. Cyanosis was noted only exceptionally. Fatigue and dyspnœa were observed in the severe cases but the great majority were without symptoms.

The physical signs within each group were surprisingly characteristic.

Group $I(a)$. The systolic murmur was the only sign of V.S.D. This murmur was systolic in time, rather highly pitched, and it ended with a normally split second sound (Fig. 2). The murmur

Aided by a grant from Swedish Life Insurance Committee for Medical Research. 


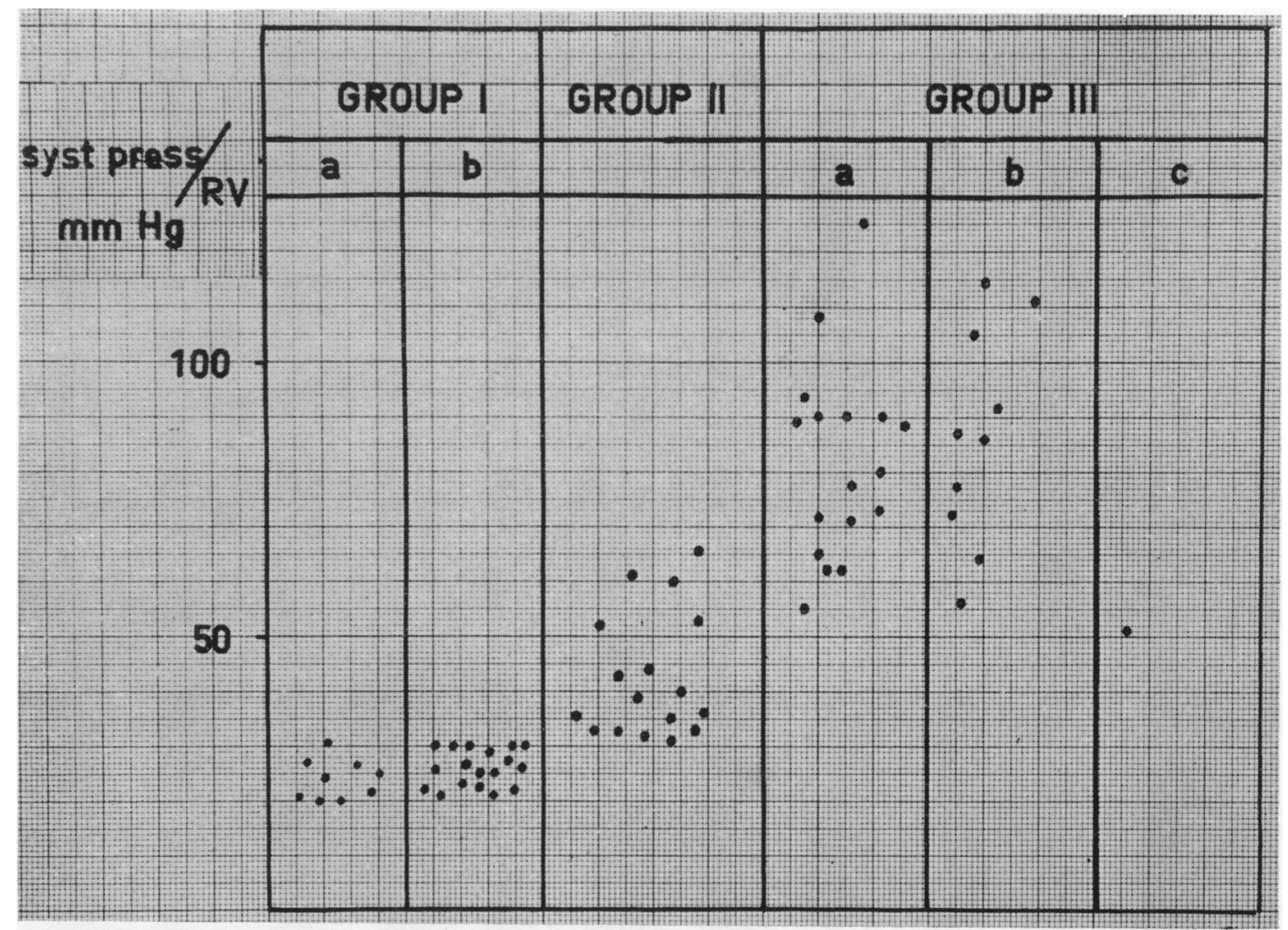

FIG. 1.-Distribution of cases in different groups of the classification.

Group I $(a)$ : normal pressure in the right ventricle without significant shunt on catheterization.

Group $\mathrm{I}(b)$ : normal pressure and significant left-to-right shunt.

Group II: moderately elevated right ventricular pressure and left-to-right shunt.

Group III $(a)$ : equilibrated pressures and left-to-right shunt.

Group III $(b)$ : equilibrated pressures and mixed shunt.

Group III $(c)$ : single ventricle.

was often localized to a distinct area at the third to fourth left interspaces and it was rather sparsely transmitted to other areas. There were no signs of cardiac enlargement.

Group $I(b)$ (normal pressure and a significant left-to-right shunt). In this group physical signs were similar to those in Group 1 $(a)$. However, the systolic murmur was often more intense and extended as a rule throughout systole (Fig. 3). In some cases the palpation of the apex beat showed slight left ventricular predominance.

Group II (moderately raised right ventricular pressure). In these patients a heaving cardiac impulse was often found. The systolic murmur was harsh and the second sound more accentuated with a very short interval between the aortic and pulmonary components (Fig. 4). Some of the cases also presented a faint mid-diastolic apical murmur.

Group III(a) (equilibrated pressures and left-to-right shunt). The systolic murmur was loud with a marked thrill; the cardiac impulse was heaving and a more or less pronounced præcordial bulge was present. The second sound over the pulmonary orifice was much accentuated and not clearly split (Fig. 5).

Group III(b) (equilibrated pressure and mixed shunt). In these cases the flow decreased owing to high pulmonary resistance and consequently the systolic murmur was faint but was followed by a highly accentuated second sound which was not split and which was very often palpable in the second left interspace. In a few cases there were no murmurs at all (i.e. " silent V.S.D.") (Fig. 6). 

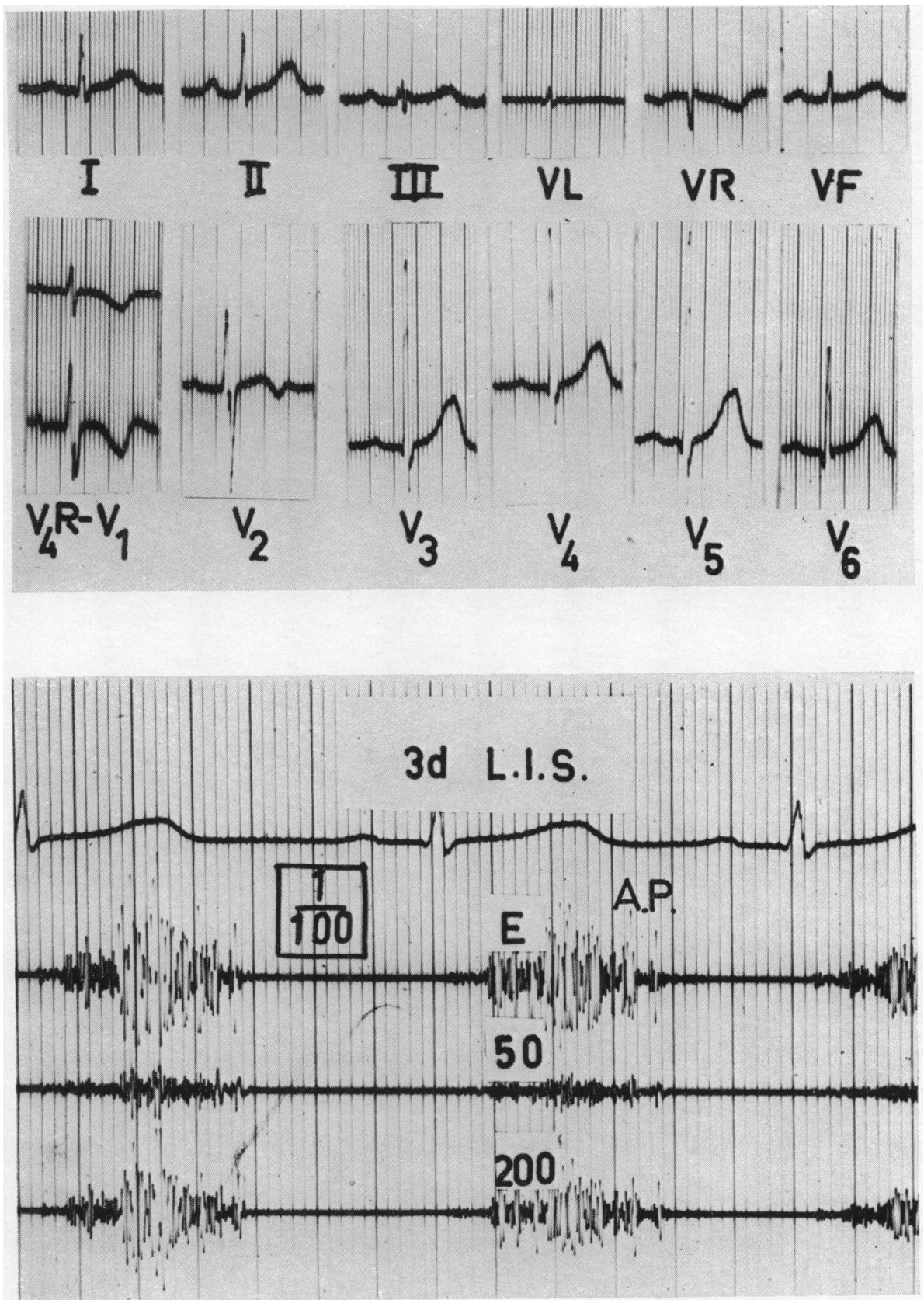

FIG. 2.-Electrocardiogram and phonocardiogram in V.S.D. with normal right ventricular pressure and insignificant shunt. Group I (a) (Girl, 3 years, D.S. 520805).

Normal EC. PCG reveals a high-pitched systolic murmur and a normally split second sound. $A$ and $P$ : aortic and pulmonary components of the second sound. E: earlike tracing. Boxed figures indicate the degree of amplification. Other figures denote standard frequencies of the filters. LIS: left intercostal space.

Pressures: mm. Hg: R.V. 20/2, P.A. $19 / 7$.

Oxygen contents: vol. $\% \mathrm{O}_{2}$ : R.A., 11·5; R.V., 11.8; P.A., 11·8. 

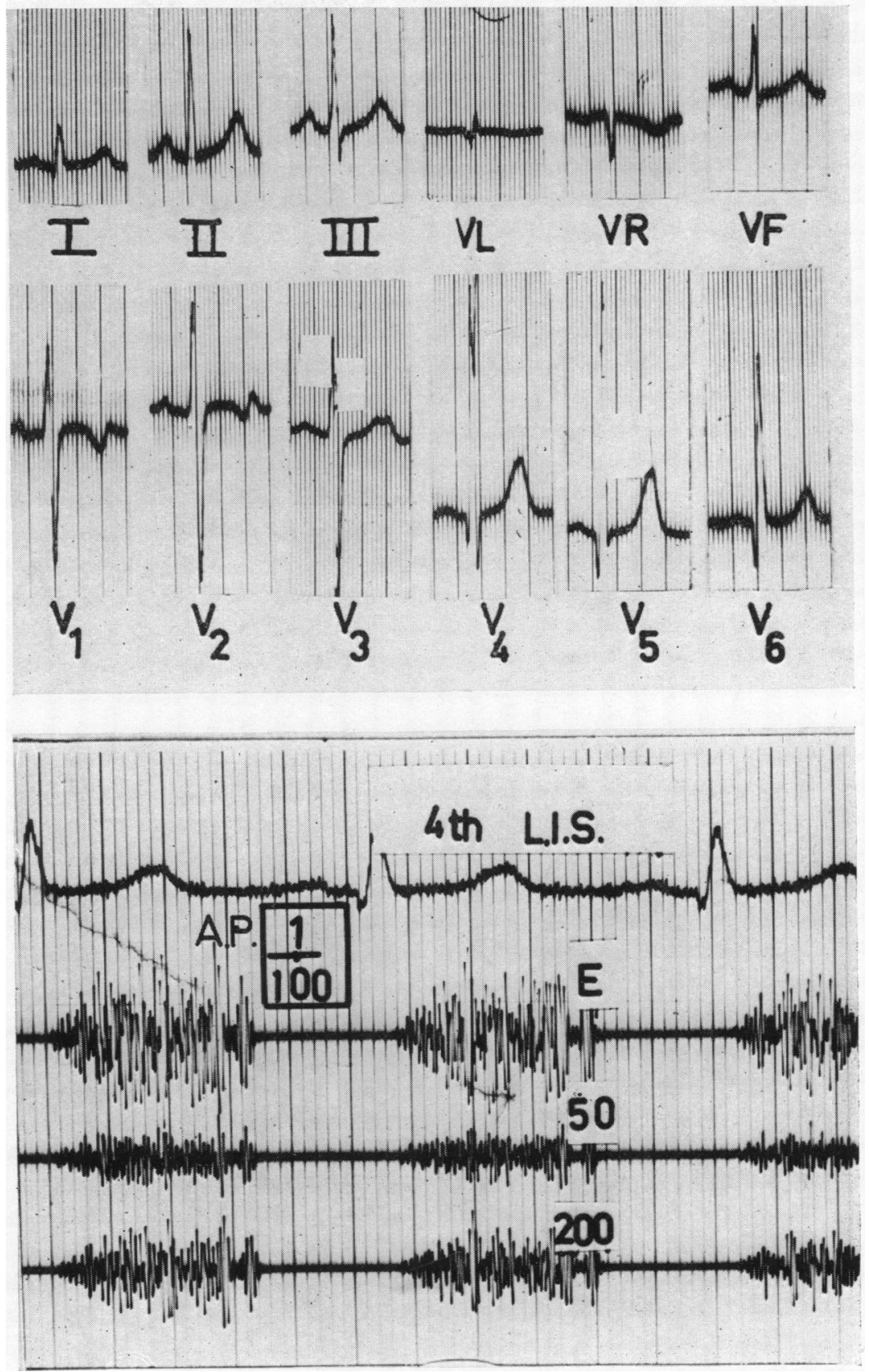

FIG. 3.-Electrocardiogram and phonocardiogram in V.S.D. with normal right ventricular pressure and significant shunt. Group $\mathrm{I}(b)$. (Girl, 9 years, D.S. 461019).

EC shows $R$ wave amplitude in V5 and V6 at upper limits of normal variation. Deep Q in V6. PCG shows systolic murmur of high amplitudes and normally split second sound. For explanation of signs see Fig. 2.

Pressures: mm. Hg: R.V. 22/3, P.A. 17/6.

Oxygen contents: vol. $\% \mathrm{O}_{2}$ : R.A., $9 \cdot 8$; R.V., $12 \cdot 1$; P.A., $11 \cdot 1$ 


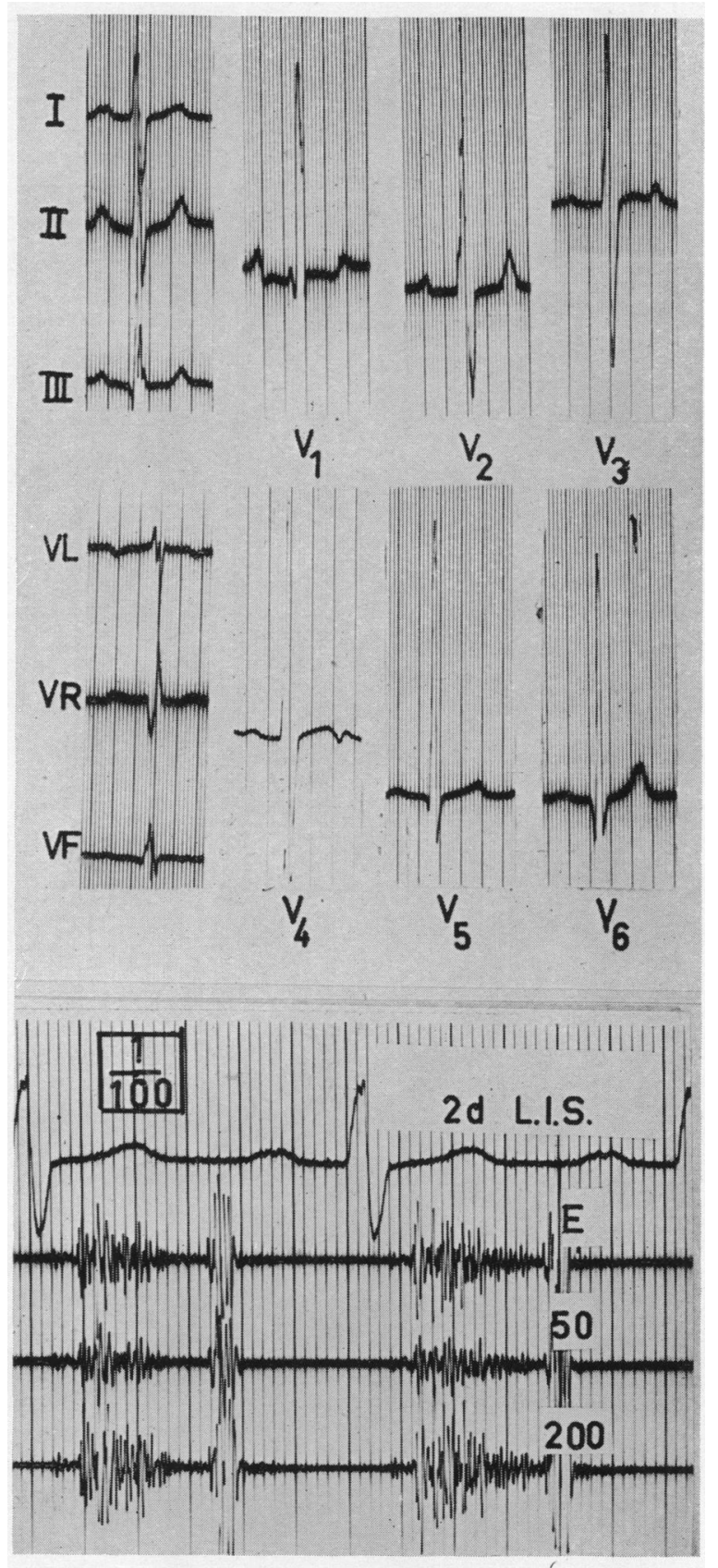

FIG. 4.-Electrocardiogram and phonocardiogram in V.S.D. with elevated right ventricular pressure and significant shunt. Group II.

(Girl, 11 years, B.J. 430527).

$\mathrm{EC}$ in V1 shows rsR's' pattern and in V3 and V4, high $R / S$. In V5 and V6 half amplitude $\left(1 \mathrm{MV}=\frac{1}{2} \mathrm{~cm}\right.$.). Interpretation: Combined ventricular hypertrophy. PCG over pulmonary area shows systolic murmur and accentuated, not definitely split, second sound. For explanation of signs see Fig. 2.

Pressures: mm. Hg: R.V. 61/6, P.A. 54/28.

Oxygen contents: vol. $\% \mathrm{O}_{2}$ : R.A., 10.6; R.V., 13.1 ; P.A., 13.1; F.A., 95\% saturation. 

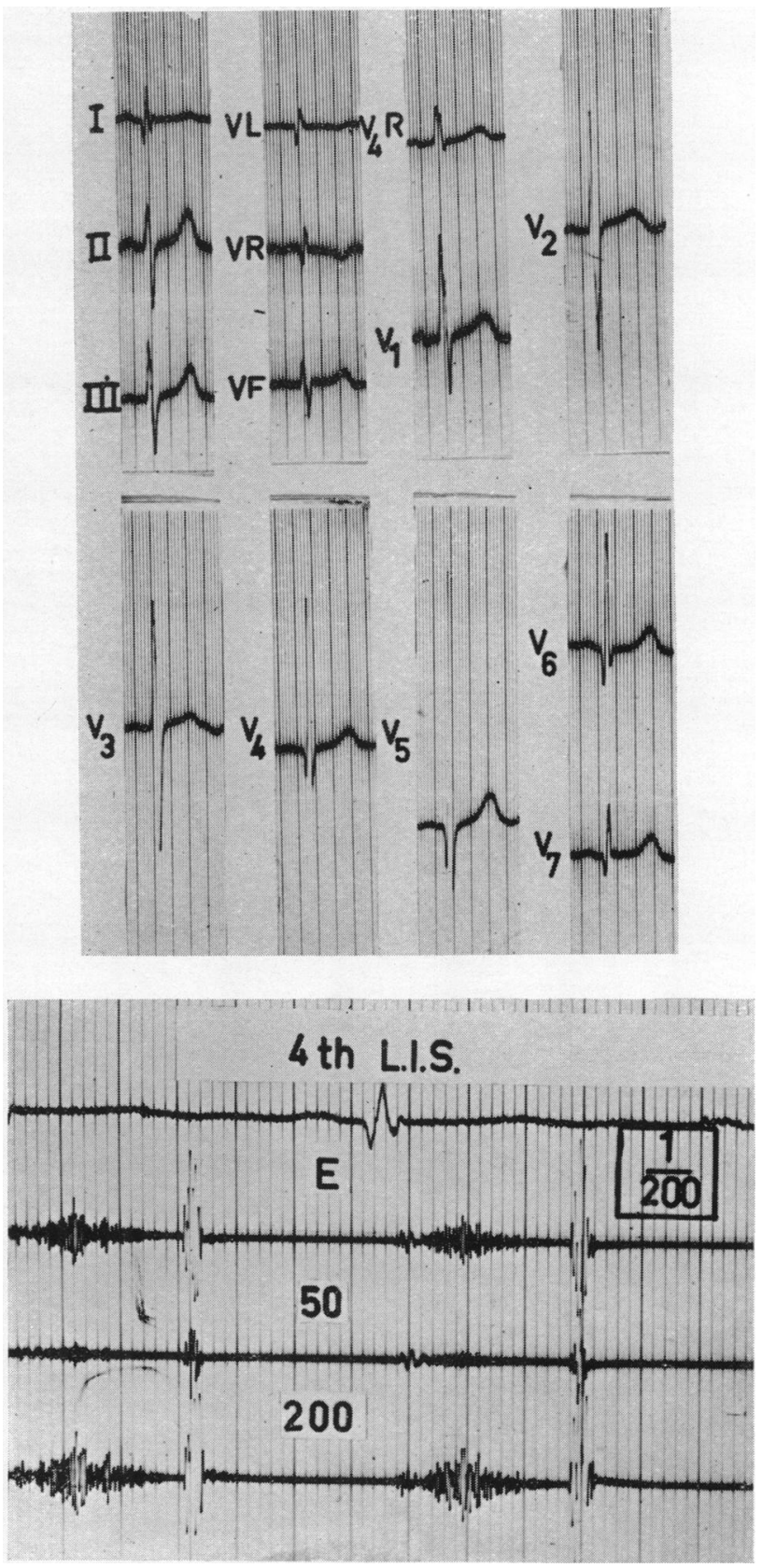

Fig. 5.-Electrocardiogram and phonocardiogram in V.S.D. with equilibrated pressures and left-to-right shunt. Group III $(a)$.

(Boy, 5 years, E.H. 490114).

EC shows combined ventricular hypertrophy: RS pattern in V1: large R/S in V2 and V3 and high $R$ waves in V5 Half amplitudes in V2, V3, and V4 $\left(1 \mathrm{MV}=\frac{1}{2} \mathrm{~cm}\right.$.). PCG shows moderately loud systolic murmur and accentuated (not split) second sound. For explanation of signs see Fig. 2.

Pressures: mm. Hg: R.V. 71, P.A. 81.

Oxygen contents: vol. $\% \mathrm{O}_{2}$ : R.A., 10.3; R.V., 12.5; P.A., 12.6; F.A., $91 \%$ saturation. 

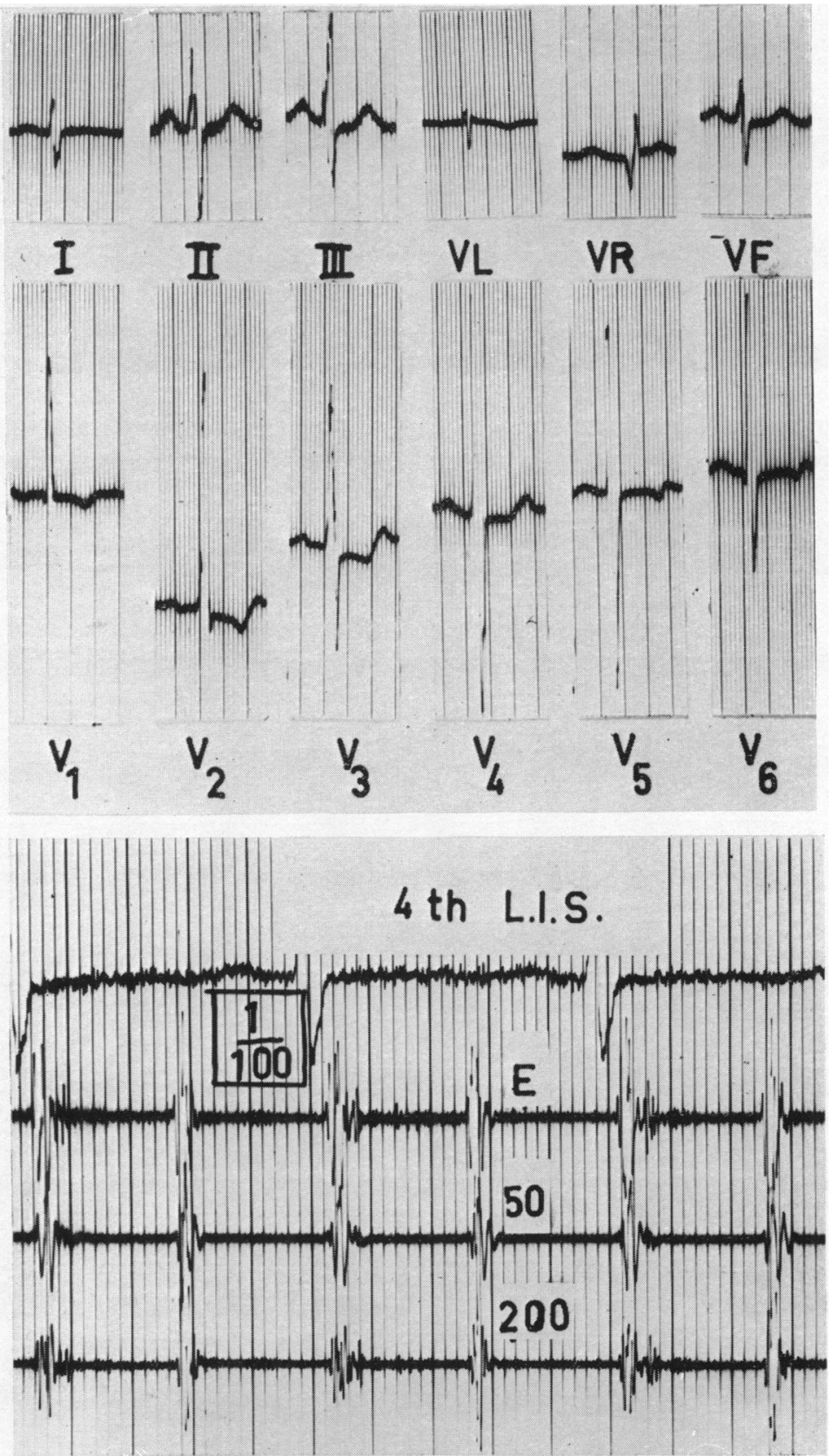

Fig. 6.-Electrocardiogram and phonocardiogram in V.S.D. with equilibrated pressures and mixed shunts. Group III $(b)$.

(Girl, 3 years, T.B. 520323).

EC shows combined ventricular hypertrophy (right hypertrophy more pronounced): RS pattern in V1, large $\mathbf{R} / \mathbf{S}$ in V3-V5 and qRS pattern in V6. PCG over the fourth left intercostal space shows a highly accentuated (not split) second sound. The systolic murmur is very faint (" silent V.S.D."). For explanations of signs see Fig. 2. Pressures: mm. Hg: R.V. 91/6, P.A. 92/62.

Oxygen contents: vol. $\% \mathrm{O}_{2}$ : S.V.C., $11 \cdot 9$; I.V.C., $12 \cdot 4$; R.A., 12·2; R.V., 12.4; P.A., $12 \cdot 1$; F.A., $81 \%$ saturation. 
A parasternal lift along the left sternal border was indicative of right ventricular hypertrophy. In this group are also included some cases with loud murmurs, large left-to-right shunts, and unsaturation of the arterial blood (see Catheterization).

Group III(c) (complete mixture of the blood: single ventricle). Only one case in this group has been observed.

It seems obvious that mild cases of V.S.D. present a normally split second sound. In pulmonary hypertension, on the other hand, the pulmonary valves close earlier and consequently the second sound is accentuated and pure. This relationship was known earlier (Wood, 1955) and it was a constant and reliable sign in our patients. Thus a split second sound was absent in 22 out of 69 cases examined phonocardiographically. In these 22 instances the pressure in the pulmonary artery exceeded $50 \mathrm{~mm}$. $\mathrm{Hg}$. On the other hand, in only 4 out of the remaining 37 cases with a split second sound was the pulmonary artery pressure above $50 \mathrm{~mm} . \mathrm{Hg}$.

Electrocardiography. The determination of normal electrocardiograms was made according to Ziegler (1951). Right and left ventricular hypertrophy were diagnosed according to Marsico et al. (1955).

The principal cardiographic changes are summarized in Table 1.

TABLE I

Electrocardiograms IN 72 CASES OF V.S.D.

\begin{tabular}{|c|c|c|c|c|c|c|c|c|c|c|}
\hline \multirow{2}{*}{ Group } & \multirow{2}{*}{$\begin{array}{l}\text { No. } \\
\text { of } \\
\text { cases }\end{array}$} & \multirow{2}{*}{ Normal } & \multirow{2}{*}{ Abnormal } & \multicolumn{3}{|c|}{$\begin{array}{l}\text { Auricular enlargement } \\
\text { and hypertrophy }\end{array}$} & \multirow{2}{*}{$\begin{array}{c}\text { Incomp. } \\
\text { A-V } \\
\text { block } \\
\text { (grade I) }\end{array}$} & \multicolumn{3}{|c|}{$\begin{array}{l}\text { Ventricular } \\
\text { hypertrophy }\end{array}$} \\
\hline & & & & $\begin{array}{l}\text { Right } \\
\text { only }\end{array}$ & $\begin{array}{l}\text { Left } \\
\text { only }\end{array}$ & $\begin{array}{c}\text { Combined } \\
\mathbf{R}+\mathbf{L}\end{array}$ & & $\begin{array}{l}\text { Right } \\
\text { only }\end{array}$ & $\begin{array}{l}\text { Left } \\
\text { only }\end{array}$ & $\begin{array}{c}\text { Combined } \\
\mathbf{R}+\mathbf{L}\end{array}$ \\
\hline $\mathrm{I}(a)$ & 9 & 8 & 1 & & & & 1 & & & \\
\hline $\mathbf{I}(b)$ & 18 & 12 & 6 & & 2 & & 1 & & 6 & \\
\hline II & 17 & 6 & 11 & & 1 & 1 & 4 & - & 3 & 7 \\
\hline $\operatorname{III}(a)$ & 17 & - & 17 & 5 & 6 & & 3 & 2 & 1 & 14 \\
\hline $\operatorname{III}(b)$ & 10 & - & 10 & 6 & 2 & & 1 & 2 & - & 8 \\
\hline $\mathrm{III}(c)$ & 1 & 0 & 1 & & 1 & & & - & 1 & - \\
\hline Total & 72 & 26 & 46 & 11 & 12 & 1 & 10 & 4 & 12 & 29 \\
\hline
\end{tabular}

In Group I $(b)$ one-third of the cases showed left ventricular hypertrophy (Fig. 3). In Group II the incidence of left ventricular hypertrophy was higher and it was often combined with right ventricular hypertrophy (Fig. 4). The cardiograms in Group III were all abnormal with signs of ventricular hypertrophy (Fig. 5 and 6). A deep $Q$ wave in V6 and high amplitudes of the R/S pattern in V2-V4 were noticed in most of the abnormal electrocardiograms (Fig. 3-6).

One case of auricular flutter was observed. Left atrial enlargement was present in 13 cases with large left-to-right shunts. Right atrial hypertrophy was seen in 12 cases with pulmonary hypertension. Finally, 10 cases of incomplete A-V block (Grade 1) were found.

Roentgenologic Examination. Kjellberg and Rudhe (1955) have published a detailed description of the radiological and angiocardiographic findings, so only a short summary of their observations need be given here.

In cases with normal right ventricular pressure the X-ray appearance was on the whole normal. With increased flow and right ventricular pressure the heart became enlarged; there was increased pulsation in the pulmonary artery and its branches and the left atrium was dilated. Left atrial enlargement was of diagnostic value as it indicated the presence of the shunt below the level 
of the atria. With increased resistance in the lesser circulation the peripheral vessels of the lungs were often narrow, the right ventricle became enlarged, and was seen in the lateral view to bulge against the thoracic wall. When hypertrophy of the left ventricle was present it could seldom be demonstrated radiologically.

In cardiac catheterization blood gas analyses and pressure determinations were of high diagnostic importance and the classification given above was based upon the hæmodynamic findings (Fig. 1).

Passage of the catheter through the defect was rarely successful. When the aorta was reached it was often difficult to judge if the catheter had passed through the defect or directly into the overriding aorta. Except in Group I $(a)$ the blood gas analyses were decisive for the diagnosis. However, difficulties were encountered. In some cases of atrial septal defect a higher oxygen content was found in the right ventricle than in the right atrium, probably due to a failure to get a good mixed sample in the right atrium. In some cases of V.S.D. a higher oxygen content was noted in the outflow tract of the right ventricle and even in the pulmonary artery. All these difficulties must carefully be taken into consideration. The systolic pressure in the right ventricle is shown in Fig. 1. It will be seen that there are patients in Groups II and III with about the same right ventricular pressures, i.e. between 50 and $70 \mathrm{~mm}$. $\mathrm{Hg}$ systolic. This depends on the fact that some of those belonging to Group III were young babies and children and consequently had a relatively low systemic pressure.

In Fig. 7 is shown the correlation between the pressure in the lesser circulation and the difference in oxygen content between the pulmonary artery and right atrium, i.e. the size of the left-to-right shunt. It can be seen that a clear-cut shunt may be present without any increased pressure. In Groups II and III (elevated pressure and left-to-right shunt) the pressure increases on the whole with increased shunt. The correlation was highly significant $(p<0.001)$. In Group III $(b)$ (equilibrated

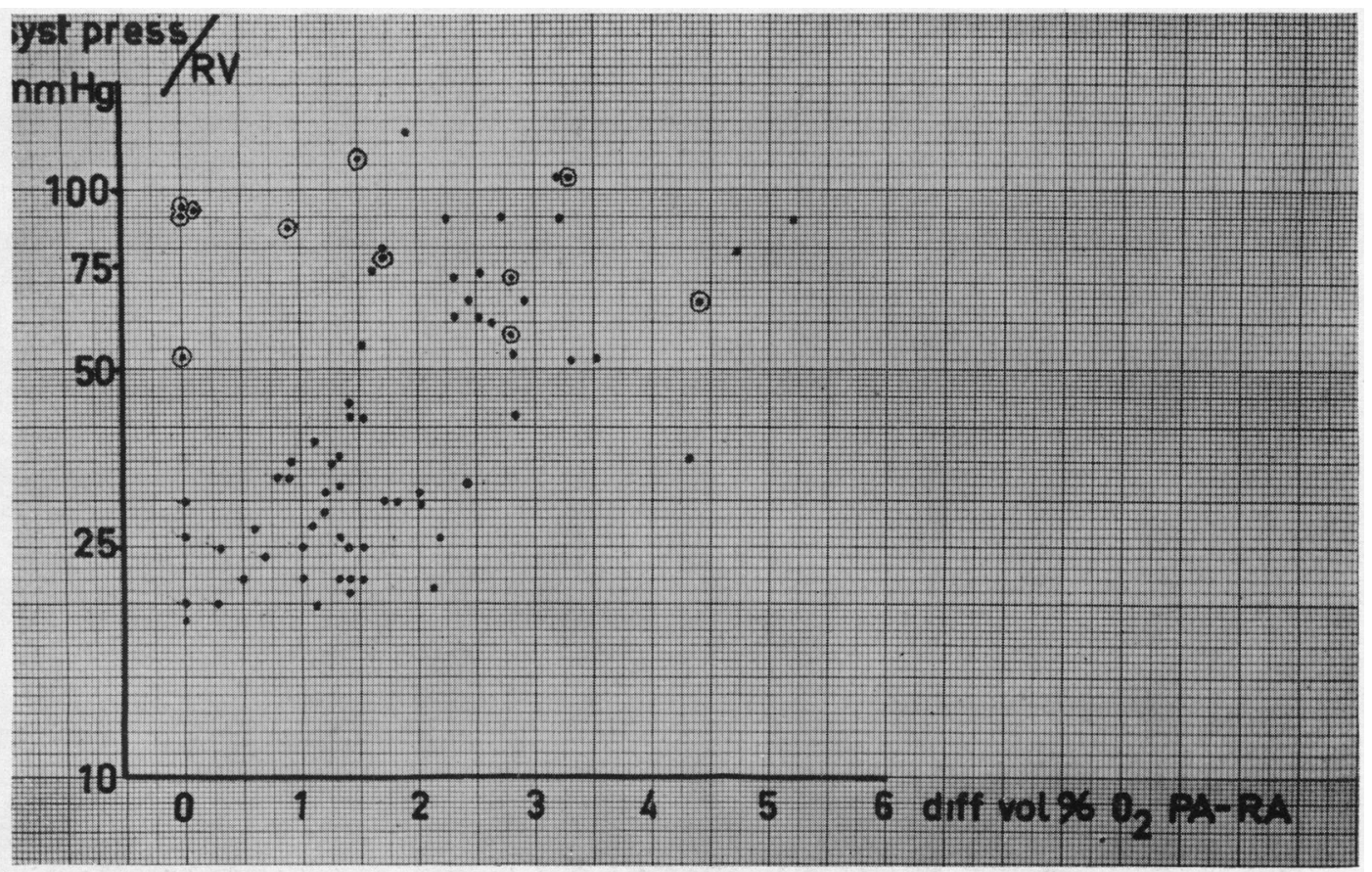

Fig. 7.-Correlation of the size of the left-to-right shunt $\left(\mathrm{O}_{2}\right.$ diff. P.A.-R.A. $)$ with the right ventricular pressure. $0=$ cases belonging to groups I, II, and III $(a)$. $\odot=$ cases belonging to group III $(b)$. 
pressure and mixed shunt) there was no correlation between the systolic pressure in the right ventricle and the size of the shunt. There are cases without any left-to-right shunt (silent V.S.D.), some other instances with a slight shunt, and finally a small group of patients with a large shunt into the right ventricle. These latter cases have been classified in Group III $(b)$ because they showed unsaturation of their arterial blood. Some of these patients may have had impaired pulmonary oxygen diffusion-a view that has been criticized by other authors (Selzer, 1951, 1954). However, unsaturation of pulmonary venous blood has been shown to exist in both atrial and ventricular septal defects in small children (Jonsson, 1955). In some cases the defect is located between the left ventricle and the infundibular part of the right ventricle (so-called infundibular septal defects). As the roots of the aorta and the pulmonary artery are placed closely to each other with one common outflow tract good pre-requisites are present for a mixed shunt.

Angiocardiography. Direct visualization of the defect by rapid injection of contrast medium into the right ventricle was impossible if the systolic pressure there was below $50 \mathrm{~mm}$. $\mathrm{Hg}$. Injection from the left ventricle could only rarely be done and injection from the left atrium gave no information owing to dilution of the contrast medium.

In cases with equilibrated pressure and especially in cases in which murmurs were absent or very faint, and in which left-to-right shunts were small or insignificant, angiocardiography was often the key to the diagnosis (see below).

\section{Discussion}

The clinical diagnosis of isolated V.S.D. does not offer any great difficulties when the systolic pressure in the right ventricle is not equilibrated, i.e. Groups $\mathrm{I}(a), \mathrm{I}(b)$, and II. An infundibular stenosis, either isolated or combined with V.S.D., is the only other malformation giving a similar clinical picture. The phonocardiogram may be valuable as a pathologically split second sound (Mannheimer et al., 1954, and Kjellberg et al., 1955) is usually present in infundibular stenosis in addition to the cardiogram showing right ventricular hypertrophy. The withdrawal pressure curve from the pulmonary artery through the infundibular chamber into the right ventricle is also characteristic. Finally, selective angiocardiography will show the anatomical details.

The cases belonging to Group III can be confused with two other conditions, namely, atypical patent ductus arteriosus and primary pulmonary hypertension. Clinically these differentiations are extremely difficult. Cardiac catheterization and angiocardiography give the correct answer.

The question arises as to the possibility of judging the prognosis from the findings on examination in the different classification groups.

According to the present classification (Fig. 1) the severity of the disease increases progressively from Group I to Group III. Functional disturbances are absent or minimal in Group I while in Group III such changes are pronounced. Our findings suggest that information about the severity might also be gained from clinical data, phonocardiography and electrocardiography. A loud systolic murmur and a normally split second sound together with a cardiogram that is either normal or showing only slight left ventricular hypertrophy speak in favour of a V.S.D. that has not yet produced any significant circulatory disturbances. On the other hand a faint murmur with a second sound accentuated but not split, and a clearly abnormal cardiogram are characteristic of rather severe hæmodynamic changes. So it seems reasonable to assume that the prognosis in patients belonging to Group III is poor and that it is rather good in those of Group I. The outlook in Group II is intermediate.

The only correct way to make a real prognostic study of our 72 cases is a sufficiently long follow-up. As this pre-requisite was not available we tried an alternative method. We studied 14 records with a suspected diagnosis of V.S.D. These belonged to patients, who were admitted to the Norrtull's pediatric clinic, Stockholm, 20-25 years ago. At that time the diagnosis was made by auscultation. Of these 14 cases one died of brain tumour: the heart was normal. One case was a combination of atrial septal defect and mild 
valvular pulmonary stenosis. Another was a typical case of tetralogy of Fallot. Two cases-19- and 20-year old women-had ventricular septal defects with normal pressures in the right ventricle: both were included in this study in Group $\mathrm{I}(b)$. The remaining ten cases were all re-examined by us recently. All showed normal auscultatory findings, normal cardiograms and phonocardiograms and were diagnosed as healthy subjects. This follow-up study showed that the diagnosis of congenital heart disease was highly uncertain 20 years ago. Physiological systolic murmurs were often classified as representing congenital heart disease.

From other quarters (Engle, 1954; Edwards, 1954) it has been pointed out that the mortality in V.S.D. during the first year of life is high. After this age the prognosis is said to be better. Our four deaths were all small children aged one to two years and classified in Group III. One of them, a boy of nearly two years died after attempted intracardiac operation. The remaining three had large hearts, were dyspnœic even at rest, and died during acute attacks of upper respiratory infection. The pathological findings were as follows: (i) an infundibular septal defect, (ii) a large defect in the membranous septum, and (iii) a large defect in the muscular septum (this one-and-ahalf-year-old boy had auricular flutter during life). These three cases all represent large defects situated in three different parts of the septum. They support the opinion that the size of the defect rather than its localization is of prognostic significance (Kjellberg et al., 1955; Selzer, 1954).

It has been claimed that the pulmonary resistance has a tendency to increase with age in cases with V.S.D. and large shunts (Blount et al., 1955). On the other hand Wood (1955) stated that a " high pulmonary resistance does not develop slowly over the years but is determined at or shortly after birth." We have not been able to recatheterize our patients after an interval of several years, so our findings do not permit any final conclusions. In the present material were included five patients between 16 and 20 years of age where the systolic pressures in the right ventricle were below $32 \mathrm{~mm}$. $\mathrm{Hg}$, showing that there was no increased pulmonary resistance.

During recent years intracardiac surgery has been introduced, but few operations on V.S.D. have been performed up to the present time. The question arises as to which cases are suitable for surgical treatment. In view of the very great risks that still exist no patients without pulmonary hypertension should be operated on (Group I and Group II without pronounced hypertension). It seems reasonable that cases with large left-to-right shunts and increased pulmonary artery pressure but without high resistance (partially Group II and III) ought to be chosen for surgical treatment.

\section{SUMMARY}

The findings on clinical examination and catheterization in 72 cases of isolated ventricular septal defect are presented.

Patients with V.S.D. but without pronounced hæmodynamic changes showed $(a)$ a loud systolic murmur over the third left interspace; $(b)$ a normally split second sound; and $(c)$ a normal electrocardiogram or slight left ventricular hypertrophy.

Severe cases of V.S.D. were characterized clinically by the following features.

(a) The second sound is highly accentuated over the second left interspace, and not split.

(b) The murmur may be loud throughout systole but there are instances of " silent V.S.D." with a very faint systolic murmur or no murmur at all. These latter represent high pulmonary resistance with a small shunt.

(c) The cardiogram in these cases is characterized by signs of combined left and right ventricular hypertrophy alone. In addition, both left and right auricular hypertrophy are observed in some of these patients.

A positive correlation was found between the systolic pressure in the right ventricle and the magnitude of the left-to-right shunt in all cases except those with equilibrated pressures and mixed shunts.

The question of prognosis on the basis of the present clinical and laboratory investigations is dicussed. 
When surgery has progressed so far as to make intracardiac operations free of great risk, patients with large left-to-right shunts but without high pulmonary resistance should be chosen for surgical treatment.

\section{REFERENCES}

Blount, Jr., S. G., Mueller, H., and McGord, M. G. (1955). Amer. J. Med., 18, 871.

Edwards, J. E., Dry, Th. J., Parker, R. L., Burchell, H. B., Wood, E. H., and Bulbulian, A. H. (1954). An Atlas of Congenital Anomalies of the Heart and Great Vessels. Thomas, Springfield.

Engle, M. A. (1954). Pediatrics, 14, 16.

Goldberg, H., Silber, E. N., Gordon, A., and Katz, L. N. (1951). Circulation, 4, 343.

Kjellberg, S. R., Mannheimer, E., Rudhe, U., and Jonsson, B. (1955). Diagnosis of Congenital Heart Disease. The Year Book Publ., Chicago.

Mannheimer, E., and Jonsson, B. (1954). Acta Pediatrica., Suppl. 100, 167.

Marsico, F., Penaloza, D., Tranchesi, J., Limón, R., and Sodi-Pallares, D. (1955). Amer. Heart J., 49, 188.

Selzer, A., and Lagueur, G. L. (1951). Arch. intern. Med., 87, 218. (1954). J. Amer. med. Ass., 154, 129.

Wood, P., Magidson, O., and Wilson, P. A. O. (1955). Brit. Heart J., 16, 387.

Ziegler, R. F. (1951). Electrocardiographic Studies in Normal Infants and Children. Thomas, Springfield. 